\title{
Knowledge and Attitude of Antenatal Women toward Analgesia during Labor and Their Choice for Mode of Delivery.
}

\author{
Reham Abdelwahab Mohamed \& Hamida Alm Eldien \\ Teacher at Technical Institute of Nursing Assiut University, \\ Lecturer of Obstetrics \& Gynecological Nursing Health Nursing, Faculty of Assiut University.
}

\begin{abstract}
Background Labor analgesia has rapidly gained popularity in obstetric practice. Low usage in developing world has raised concern. This study aimed to assess knowledge and attitude of antenatal women for pain relief methods during labor and to know the effect of presumed availability of relief pain on antenatal women's choice about the mode of delivery (vaginal vs. cesarean section). Subjects and methods: Cross sectional descriptive research design was utilized in the present study. Convenient sample was used among antenatal women in the third trimester who attended the antenatal clinic in Woman's Health Hospital in Assiut city. Two tools were utilized to collect data. Tool (one) was structured interview questionnaire included five parts (personal data, obstetrical history, data related to current pregnancy, data related to labor analgesia, data related to the attitude toward vaginal / cesarean section delivery).The second tool (Visual analog scale: was used to assess pregnant women's attitude towards pain (past experience of severe pain, previous and expected labor pain). Results: the results indicated that about $60.0 \%$ of the participant women preferred C.S. delivery to avoid labor pain and the majority of the sample (82.9\%) was unaware about labor analgesia. Furthermore, the availability of pain relief during labor may decrease CS by more than 50\% in women had moderate and severe labor pain during their current pregnancy compared to non-availability of pain relief (9.6\% VS $22.7 \%$ and $8.2 \%$ VS $28.1 \%$, respectively). Conclusion: It can be concluded that there is a lack of knowledge regarding the need for pain relief during labor Recommendations: the researchers recommended that the importance to educate the antenatal women about the need for labor analgesia and the available options by the provision of information leaflets, labor pain websites and childbirth preparation classes.
\end{abstract}

Key words: Knowledge, attitude, labor analgesia \& awareness.

\section{Introduction}

Normal vaginal birth for women is a painful event due to uterine contractions, recurrent vaginal examinations, and vaginal lacerations. For most women, childbirth is associated with very severe pain. The perceived pain during labour causes generalized neuroendocrinal stress response including increased oxygen consumption, hyperventilation, increased cardiac output, impaired uterine contractility, metabolic acidemia, and increased maternal-fetal mortality and morbidity (Fan et al., 2007). So, many labor pain management strategies named painless childbirth methods have been developed and widely used in recent years. Painless childbirth methods include pharmacologic (such as regional anesthesia, paracervical block, pudendal block, and systemic analgesia) and nonpharmacologic methods (such as psychoprophylactic method, hypnosis, and acupuncture) (Orange, et al., 2012).

Caesarean sections are one of the most frequently performed operations in women (Gita, 2008). One of the most dramatic features of modern obstetrics is the relentless increase in the CS rate. This escalating CS rate is a major public health problem because caesarean section increases the health risk for mothers and babies as well as the cost of health care compared with normal deliveries. There are many indications for elective caesarean section. Caesarean section on demand is one of these indications (Ajeet, et al., 2011).

It is difficult to pinpoint an exact cause for the rising rates of Caesarean sections. Medical, Institutional, legal, psychological, socio-demographic factors or non-medical reasons such as fear of labor pain, the belief that delivery by caesarean ensures protection of the baby's brain or inadequate pain relief techniques during labor play a contributing role (International Institute for Population Sciences and ORC, 2006). Natural labor and its pain is probably the most painful event in the lives of women. Consequently the majority of women today requires and use some form of analgesia during labor. Several methods of labor analgesia have evolved over the years, but pain relief in labor is still controversial (Mugambe, et al., 2007). In developed countries the issue is focused on the choice of methods and complications, while in developing countries, the issues revolve around awareness, acceptability and availability of labor 
analgesia (Naithani, et al., 2011). In addition to fear of child birth women may not be aware of the analgesic options for labor. Culture, ethnic group, age and education may have a strong influence on the attitude toward pain relief in labor (Henry and Nand, 2004).

Pain relief management during labor has undergone various advancement since 1847, when Simpson found that chloroform could help relieve the pain women felt during labor. His findings were not received favorably on religious and medical grounds. Childbirth was viewed as a physiological process best managed with as little interference as possible. Pain relief is the effective and helpful ways of reducing the amount of pain you feel with contractions. The effect varies from woman to woman. This may involve the use of pharmacological or nonpharmacological techniques or a combination of these methods (Barakzai et al., 2010).

Pharmacological methods include (1- Inhalation analgesia such as Nitrous Oxide gas. 2-Opioid or Narcotics drugs such as Morphine is given through an intravenous (IV) infusion or it can be injected under the skin or into muscle, Fentanyl is a shorter acting narcotic and given as a single dose. Remifentanil is a very short acting narcotic. 3- Local anesthetic and nerve block techniques during childbirth frequently used to numb nerves in the vaginal area. 4- Regional analgesia/anesthesia involves techniques that block pain nerves from the uterus and birth canal with the use of local anesthetics: this includes epidural, spinal, and combined spinal and epidural (CSE) techniques. 5- General anesthesia: this is reserved for emergency situations during vaginal deliveries and for some caesarean sections (Health Sciences Centre, 2008).

\section{Significance of the study}

In Egypt, rise in cesarean deliveries occurred for all births, from a low of 4.6 percent in 1992 to 10.3 percent in 2000. Although the cesarean section rate was slightly higher in private hospitals, the rate also increased consistently in public hospitals. In Assiut University Hospital the most recent clinical audit showed that CS rate was 32\% in 2008 and $36 \%$ in 2011. Increasing rates of birth by caesarean section are an issue of concern among public health officials and the medical community in many countries (Abdel-Aleem et al., 2011).

Women may change their preferred delivery method due to fear of labour pain and this is one of the most important reasons of the increase in the rate of elective cesarean section in recent years. Studies have shown that women with fear of childbirth require more use of pain relieving methods in labour compared to women without fear of childbirth (Hildingsson, et al., (2002).

\section{Aims of the study}

This study aimed to:

1. Assess knowledge and attitude of antenatal women for pain relief methods during labor.

2. Know the effect of presumed availability of relief pain on antenatal women's choices about the mode of delivery (vaginal vs. cesarean section).

\section{Research question}

What is the effect of presumed availability of relief pain on antenatal women's choices about the mode of delivery (vaginal vs. cesarean section)?

\section{Subjects and Method}

\section{Technical design \\ Research design}

A descriptive research design was utilized in this study.

\section{Setting of study}

The study was conducted in the antenatal clinic in Woman's Health Hospital in Assiut University. This clinic serves all women who attended to it. Services which provided to women in this clinic; abdominal examination, PV examination, laboratory tests (pregnancy test, urine analysis, hemoglobin concentration, and sugar test), Ultrasonography services, Electronic fetal heart rate monitoring and the physician admit the cases that require hospitalization. The antenatal clinic works all days a week. This clinic receives women from 8 am to $1 \mathrm{pm}$. Subjects

All convenient women in the third trimester of pregnancy attended the antenatal clinic during the period of data collection were evaluated for eligibility. Their total number was 814 women with the following inclusion criteria:

1. All pregnant women in the third trimester of pregnancy who attended the antenatal clinic in Woman's Health Hospital.

2. All pregnant women who planned to be normal delivery in Assiut University Hospital.

3. Without medical or obstetric problems.

4. Willing to participate in the study.

Tools of the study

Two tools used for data collection.

Tool (1) structured interview questionnaire sheet:

It was designed and utilized by the researchers to collect the required data from every selected woman at the selected settings. The questionnaire consisted of the following five parts:

Part (1): Personal data included: name age, address, telephone number, level of education, occupation, 
residence, religion, income and previous operations or complications from operations or anesthesia.

Part (2): Obstetrical history included: gravidity, Parity, abortions, still birth, number of living children, outcomes of last delivery (spontaneous vaginal delivery, SVD +Episiotomy, instrumental delivery, caesarean section), previous analgesia given during previous births and method of this analgesia.

Part (3): ): Data related to current pregnancy included: weeks of gestation.

Part (4): Data related to labor analgesia: to assess the women's knowledge about labor analgesia, it included women's attitude toward dealing with labor pain, women's knowledge about different methods of labor analgesia, source of information about labor analgesia, women's knowledge about the provider of labor analgesia, women's desire to have labor analgesia, the preferred method of labor analgesia and if refused their reason for this refusal.

Part (5): Data related to the attitude toward vaginal/ cesarean section delivery included: Preferred mode of delivery, Reasons for choosing to be a chance of vaginal delivery, Reasons for choosing CS on demand, Women will be asked about her choice between vaginal delivery and caesarean section if there is no pain relief during labor and in case of its availability.

Tool (2): Visual analog scale: was used to assess pregnant women's attitude towards pain (past experience of severe pain, previous and expected labor pain). The scale is named after its inventor, psychologist (Rensis, 1932). It is a measurement instrument for subjective characteristics or attitudes that cannot be directly measured and ranged from $0-10$. It was included (11) items from 0 to 10 score, 0 score represents No pain, (1,2and 3 grades) represents Mild pain, (4, 5 and 6 grades) represents Moderate pain and (7, 8, 9 and 10 grades) represents severe pain.

\section{Operational design \\ Preparatory phase}

The researcher reviewed related literature (local \& international), using text books, web articles and scientific magazines. The tools were then prepared.

\section{Validity}

The tools were reviewed for validity by 3 experts in Obstetrics and Gynecology (medical and nursing).

\section{Pilot study}

A Pilot study was conducted on 15 women during the first two weeks to test the clarity, applicability of the questions and time needed for each interview. These women were included in study sample.

\section{Field work}

The study was carried out during the period from the first of June 2013 to the end of December 2013 (average 10 women in the day). At the first meeting with the women the investigators introduced themselves, and explained the nature and aims of the study then obtained participants' oral consent. The researcher asked women the questions presented in the sheet then filled the sheet from the illiterate and educated women. Each interview took about 10-15 minutes with each woman. Finally, the investigator tolled the woman about the time of the next antenatal visit.

\section{Limitations of the study}

* Some antenatal women who meet the inclusion criteria refused to participate in the study.

* As this study was conducted at a single tertiary healthcare center, thus, limiting the reliability of data, this could have been gained from basing it in multicenter institutions.

* Most of the antenatal women surveyed were a less educated and belonged to rural areas, thus, might not necessarily reflect national obstetric population preferences.

* Unavailability of a place suitable to conduct the interview and fill the questionnaire with the women.

\section{Ethical considerations}

The investigator explained the nature and the aims of the study then an oral consent of women was obtained. Women were reassured that any obtained information was used only for the purpose of the study. A code number will be used for every woman to maintain confidentiality. The study maneuvers had no actual or potential harm on women and professional help was provided whenever needed. Also, there was no risk for participation in the study as no drug use or clinical procedure will be involved. Any participant in the study has the right to refuse answering any of the questions or to stop the interview at any time. She also had the right to withdraw from the study at any time. Woman's participation in the study had no positive or negative effect on the service she received.

\section{Administrative design}

Before conducting the study an official approval was obtained from the Dean of the Faculty of Nursing directed to the head of department of Obstetrics \& Gynecology in Women's Health Hospital, the investigator was explained the nature and the aims of the study then an oral consent of the participate was obtained.

\section{Statistical design}

The collected data was coded, tabulated and analyzed using the statistical package for social science programs (SPSS) version 16 windows Microsoft .continuous data was expressed as frequency, percentage, means and SD .Discrete data was expressed as frequency and percentage .comparison 
between variables was done using .probability $(\mathrm{P}-$

less than 0.001 was considered highly significant.

value) less than 0.05 was considered significant and

\section{Result}

Table (1): Distribution of the participants according to their Socio-demographic Characteristics.

\begin{tabular}{|c|c|c|}
\hline & Frequency $(\mathrm{N}=814)$ & Percentage $(\%)$ \\
\hline \multicolumn{3}{|l|}{ Age } \\
\hline $15-20$ years & 129 & $(15.8)$ \\
\hline 21-30 years & 546 & $(67.1)$ \\
\hline $31-40$ years & 133 & $(16.3)$ \\
\hline $41-45$ years & 6 & $(0.7)$ \\
\hline Total & 814 & $(100)$ \\
\hline$($ Mean \pm SD $)$ & \multicolumn{2}{|c|}{$26.05 \pm 5.391$} \\
\hline \multicolumn{3}{|l|}{ Educational level } \\
\hline Illiterate & 299 & $(36.7)$ \\
\hline Read and write & 41 & $(5.1)$ \\
\hline Elementary education & 145 & $(17.8)$ \\
\hline Secondary education or vocational & 246 & $(30.2)$ \\
\hline A college education & 83 & $(10.2)$ \\
\hline Total & 814 & $(100)$ \\
\hline \multicolumn{3}{|l|}{ Occupation } \\
\hline Employed & 27 & $(3.3)$ \\
\hline Not employed & 787 & $(96.7)$ \\
\hline Total & 814 & $(100)$ \\
\hline \multicolumn{3}{|l|}{ Residence } \\
\hline Rural & 480 & $(59.0)$ \\
\hline Urban & 334 & $(41.0)$ \\
\hline Total & 814 & (100) \\
\hline
\end{tabular}

Table (2): Distribution of the participants according to their Obstetric history.

\begin{tabular}{|c|c|c|}
\hline & Frequency $(\mathrm{N}=814)$ & Percentage $(\%)$ \\
\hline \multicolumn{3}{|l|}{ Parity: } \\
\hline Para $^{*} 0$ & 231 & $(28.4)$ \\
\hline Para 1 & 204 & $(25.1)$ \\
\hline Para 2,3 , or 4 & 302 & $(37.1)$ \\
\hline Para 5 or more & 77 & $(9.5)$ \\
\hline Total & 814 & (100) \\
\hline \multicolumn{3}{|l|}{ Previous delivery experience: $($ No. $=583)$} \\
\hline Participants experienced with normal delivery & 381 & $(65.3)$ \\
\hline Participants experienced with caesarean delivery & 119 & $(20.4)$ \\
\hline Participants experienced with both deliveries & 83 & $(14.3)$ \\
\hline \multicolumn{3}{|l|}{ Reasons participants prefer C.S } \\
\hline $\begin{array}{l}\text { Avoidance of pain in general and expected pain for } \\
\text { vaginal delivery }\end{array}$ & 87 & $(60)$ \\
\hline $\begin{array}{l}\text { Avoidance of a traumatic experience of previous } \\
\text { vaginal delivery }\end{array}$ & 1 & $(0.7)$ \\
\hline As advised by treating doctor & 49 & $(33.8)$ \\
\hline Other causes & 8 & $(5.5)$ \\
\hline Total & 145 & (100) \\
\hline
\end{tabular}

*Para: Number of deliveries. 
Table (3): Distribution of participants on the basis of knowledge, methods, source and provider of labor analgesia.

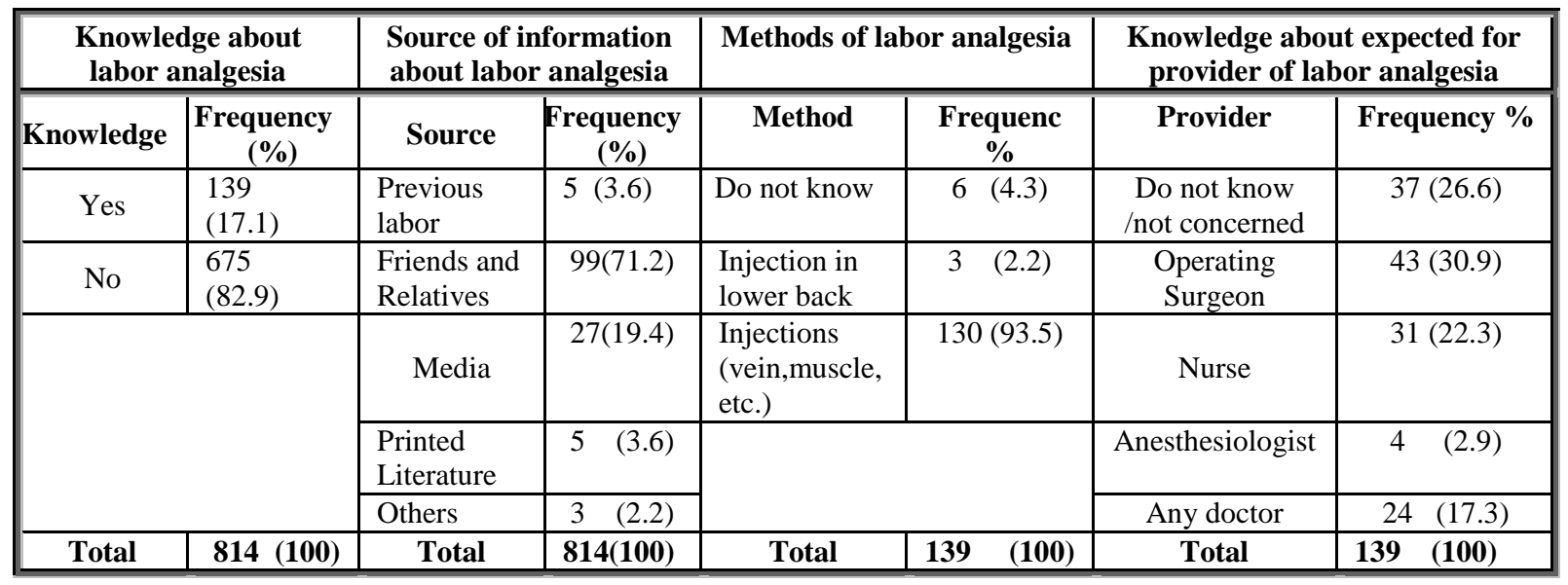

Table (4): Participants' attitude towards labor analgesia

\begin{tabular}{|c|c|c|c|c|c|c|c|c|c|}
\hline \multicolumn{6}{|c|}{ Labor pain } & \multirow{2}{*}{\multicolumn{2}{|c|}{$\begin{array}{l}\text { Participants' } \\
\text { opinion regarding } \\
\text { labor analgesia }\end{array}$}} & \multirow{2}{*}{\multicolumn{2}{|c|}{$\begin{array}{c}\text { Reason for not asking } \\
\text { for } \\
\text { labor analgesia }\end{array}$}} \\
\hline \multicolumn{2}{|c|}{$\begin{array}{l}\text { Past experience of } \\
\text { severe pain }\end{array}$} & \multicolumn{2}{|c|}{$\begin{array}{c}\text { Previous labor pain } \\
\text { experience }\end{array}$} & \multicolumn{2}{|c|}{$\begin{array}{c}\text { Expected labor } \\
\text { pain }\end{array}$} & & & & \\
\hline $\begin{array}{c}\text { Level of } \\
\text { pain }\end{array}$ & $\begin{array}{c}\text { Frequen } \\
\text { cy } \\
(\%)\end{array}$ & $\begin{array}{c}\text { Level of } \\
\text { pain }\end{array}$ & $\begin{array}{c}\text { Freque } \\
\text { ncy } \\
(\%)\end{array}$ & $\begin{array}{c}\text { Level of } \\
\text { pain }\end{array}$ & $\begin{array}{c}\text { Frequen } \\
\text { cy } \\
(\%)\end{array}$ & $\begin{array}{c}\text { Preferr } \\
\text { ed }\end{array}$ & $\begin{array}{c}\text { Freque } \\
\text { ncy } \\
(\%)\end{array}$ & Reason & $\begin{array}{c}\text { Freque } \\
\text { ncy } \\
(\%)\end{array}$ \\
\hline No pain & $1(0.1)$ & $\begin{array}{l}\text { No } \\
\text { pain }\end{array}$ & $\begin{array}{l}141 \\
(24.2)\end{array}$ & No pain & $\begin{array}{l}85 \\
(10.4)\end{array}$ & Yes & $\begin{array}{c}717 \\
(88.1)\end{array}$ & $\begin{array}{l}\text { The methods do } \\
\text { not work }\end{array}$ & $7(7.2)$ \\
\hline Mild pain & $2(0.2)$ & $\begin{array}{l}\text { Mild } \\
\text { pain }\end{array}$ & $7(1.2)$ & $\begin{array}{l}\text { Mild } \\
\text { pain }\end{array}$ & $16(2.0)$ & No & $97(11.9)$ & $\begin{array}{l}\text { The methods } \\
\text { harmful to the baby }\end{array}$ & $4 \quad(4.1)$ \\
\hline $\begin{array}{l}\text { Moderate } \\
\text { pain }\end{array}$ & $98(12.0)$ & $\begin{array}{l}\text { Moderate } \\
\text { pain }\end{array}$ & $24(4.1)$ & $\begin{array}{l}\text { Moderat } \\
\text { e pain }\end{array}$ & 97 (11.9) & & & $\begin{array}{l}\text { I want } \begin{array}{r}\text { to } \\
\text { experience normal } \\
\text { delivery }\end{array} \\
\end{array}$ & $\begin{array}{c}55 \\
(56.7) \\
\end{array}$ \\
\hline $\begin{array}{l}\text { Severe } \\
\text { pain }\end{array}$ & $713(87.6)$ & $\begin{array}{l}\text { Severe } \\
\text { pain }\end{array}$ & 411 70.5) & $\begin{array}{l}\text { Severe } \\
\text { pain }\end{array}$ & $616(75.7)$ & & & $\begin{array}{l}\text { uterine } \\
\text { contractions in the } \\
\text { case of labor } \\
\text { analgesia may be } \\
\text { weak }\end{array}$ & $2 \quad(2.1)$ \\
\hline & & & & & & & & Others & $29(29.9)$ \\
\hline Total & $814(100)$ & Total & $583(100)$ & Total & 814(100) & Total & $814(100)$ & Total & $97(100)$ \\
\hline
\end{tabular}

Other reasons for not asking for labor analgesia included, the belief that LA cause inability to push or use lower body parts, may lead to caesarean section or instrument use, the belief that methods of LA are expensive, I scared of infection, I did not see any woman had experienced with painless labor, I don't like experience anything without previous experience or I don't like injections.

Table (5): Women choice of mode of delivery in case of presumed availability and non- availability of pain relief during labor:

\begin{tabular}{|l|l|l|l|}
\hline \multicolumn{1}{|c|}{ Items } & \multicolumn{1}{|c|}{$\begin{array}{c}\text { Non- availability of pain } \\
\text { relief }\end{array}$} & \multicolumn{1}{c|}{$\begin{array}{c}\text { Availability of pain } \\
\text { relief }\end{array}$} & \multicolumn{1}{c|}{ P-value } \\
\hline Prefer Normal delivery & $629(77.3 \%)$ & $741(91.0 \%)$ & $0.001 *$ \\
\hline Prefer Caesarean section & $185(22.7 \%)$ & $73(9.0 \%)$ & $0.001 *$ \\
\hline
\end{tabular}

Chi-square test $\quad *$ statistically significant difference $(P<0.05)$ 
Table (6): The effect of the participant's expected labor pain on their choice of mode of delivery in case of presumed availability and non- availability of pain relief during labor.

\begin{tabular}{|c|c|c|c|c|c|c|}
\hline & \multicolumn{3}{|c|}{ N.D } & \multicolumn{3}{|c|}{ C.S } \\
\hline & $\begin{array}{c}\text { Availability of } \\
\text { pain relief }\end{array}$ & $\begin{array}{c}\text { Non- } \\
\text { availability of } \\
\text { pain relief }\end{array}$ & \multirow[t]{2}{*}{$\begin{array}{c}\text { P- } \\
\text { valu } \\
\text { e }\end{array}$} & $\begin{array}{l}\text { Availability } \\
\text { of pain relief }\end{array}$ & $\begin{array}{c}\text { Non- } \\
\text { availability of } \\
\text { pain relief }\end{array}$ & \multirow[t]{2}{*}{$\begin{array}{c}\text { P- } \\
\text { value }\end{array}$} \\
\hline & No. $(\%)$ & No. $(\%)$ & & No. $(\%)$ & No. $(\%)$ & \\
\hline \multicolumn{3}{|c|}{ Expected labor pain } & \multirow{6}{*}{$\begin{array}{l}\stackrel{0}{8} \\
\stackrel{8}{*}\end{array}$} & & & \multirow{6}{*}{$\stackrel{\circ}{\stackrel{8}{8}}$} \\
\hline - No pain & $29 \quad(3.9 \%)$ & $(0.8 \%)$ & & $\begin{array}{ll}56 & (76.7 \%)\end{array}$ & $\begin{array}{ll}80 & (43.2 \%)\end{array}$ & \\
\hline - Mild pain & $12 \quad(1.6 \%)$ & $(0.8 \%)$ & & $4 \quad(5.5 \%)$ & $\begin{array}{ll}11 & (5.9 \%)\end{array}$ & \\
\hline - Moderate pain & $90 \quad(12.1 \%)$ & $55 \quad(8.7 \%)$ & & $7 \quad(9.6 \%)$ & $42 \quad(22.7 \%)$ & \\
\hline - Severe pain & $610(82.3 \%)$ & $564(89.7 \%)$ & & $\begin{array}{ll}6 & (8.2 \%) \\
\end{array}$ & $\begin{array}{ll}52 & (28.1 \%) \\
\end{array}$ & \\
\hline Total & $741(100.0 \%)$ & $629(100.0 \%)$ & & $73(100.0 \%)$ & $185(100.0 \%)$ & \\
\hline
\end{tabular}

Table (7): Relation between the participants' parity and their knowledge about labor analgesia.

\begin{tabular}{|c|c|c|c|c|c|c|c|}
\hline & \multicolumn{4}{|c|}{ Knowledge about labor analgesia } & \multirow{2}{*}{\multicolumn{2}{|c|}{ Total }} & \multirow{3}{*}{ P-value } \\
\hline & \multicolumn{2}{|c|}{ No } & \multicolumn{2}{|r|}{ Yes } & & & \\
\hline & No. & $\%$ & No. & $\%$ & No. & $\%$ & \\
\hline \multicolumn{8}{|l|}{ Parity } \\
\hline Para 0 & \multicolumn{2}{|c|}{$199 \quad(29.5 \%)$} & \multicolumn{2}{|c|}{$\begin{array}{ll}32 & (23.0 \%) \\
\end{array}$} & 231 & $(28.4 \%)$ & \multirow{5}{*}{0.380} \\
\hline Para 1 & \multicolumn{2}{|c|}{$170 \quad(25.2 \%)$} & \multicolumn{2}{|c|}{$34 \quad(24.5 \%)$} & \multicolumn{2}{|c|}{$204 \quad(25.1 \%)$} & \\
\hline Para 2,3 , or 4 & \multicolumn{2}{|c|}{$3 \quad(36.0 \%)$} & \multicolumn{2}{|c|}{$59 \quad(42.4 \%)$} & \multicolumn{2}{|c|}{$(37.1 \%)$} & \\
\hline Para 5 or more & 63 & $(9.3 \%)$ & \multicolumn{2}{|c|}{$14 \quad(10.1 \%)$} & \multicolumn{2}{|c|}{$(9.5 \%)$} & \\
\hline Total & \multicolumn{2}{|c|}{675 (100.0\%) } & \multicolumn{2}{|c|}{$139(100.0 \%)$} & $814 \quad(1$ & $(100.0 \%)$ & \\
\hline
\end{tabular}

Table (1) : shows that the socio-demographic characteristics of the studied antenatal women. The mean age of antenatal women was (26.1) year, more than two thirds $(67.1 \%)$ of the women ranged from (21-30 years). Regarding to the level of education more than one third (36.7\%) of the study group were illiterate and it was observed that the vast majority (96.7\%) of them were not employed. As regards to residence, more than half $(59.0 \%)$ of them live in rural areas, while more than one third (41.0\%) live in urban area.

Table (2) : illustrate the distribution of the studied antenatal women by their Obstetric profile. According to the studied antenatal women parity, more than one third (37.1\%) of women were multipara while slightly less than one tenth $(9.5 \%)$ were grand multipara. With regard to the previous deliveries experience of the antenatal women who took part in the study, about tow thirds $(65.3 \%)$ in the study group had at least one experience with normal delivery, slightly less than one quadrant $(20.4 \%)$ had one experience with cesarean section. Also, the same table indicated that about $60.0 \%$ of the participant women preferred C.S. delivery to avoid labor pain. Concerning knowledge about labor analgesia table (3) : shows that the majority of the sample $(82.9 \%)$ was unaware about labor analgesia. the vast majority women who were aware about labor analgesia $(93.5 \%)$ knew that LA was provided by injections (vein, muscle, etc.) Nearly one third (30.9\%) described the provider of labor analgesia as operating surgeon, while the minority (2.9\%) described the provider of LA as an anesthesiologist. Regarding to source of information about LA, we observe from this table that nearly three quadrants $(71.2 \%)$ of the study group obtained the information from friends and relatives, while slightly less than one fifth (19.4\%) obtained information from audio, visual, or audiovisual media and only (3.6\%) obtained information from printed literature

Table (4) shows participants' attitude towards labor analgesia. It was found that the majority $(87.6 \%)$ of the studied group had severe pain in their past experiences. Regarding to previous labor pain, slightly less than three quarters $(70.5 \%)$ of the studied antenatal women who had previous labors had severe previous labor pain. As regard to expected labor pain, slightly more than three quarter $(75.7 \%)$ of the study group had expected that their labor pain 
will be severe in the current pregnancy, while the minority $(2.0 \%)$ had expected mild labor pain in the current pregnancy. By shedding light on the participants opinion regarding LA, only $(11.9 \%)$ of the study group refused receiving any forms of analgesia during labor of their current pregnancy. Among the previous refusing women, the most common reason for refusal $(56.7 \%)$ was the desire of antenatal woman to experience normal delivery.

Table (5): illustrates when the option of nonavailability of LA offered, slightly more than three quadrants $(77.3 \%)$ of the studied antenatal women opted to give birth normally and slightly less than one quadrant $(22.7 \%)$ opted to give birth by C.S. On the other side when the option of availability of LA offered, the vast majority $(91.0 \%)$ of the studied antenatal women opted to give birth normally and slightly less than one tenth $(9.0 \%)$ opted to give birth by C.S. with statistically significant differences (P. $0.001)$.

Table (7) : illustrates the effect of the participant's expected labor pain on their choice of mode of delivery in case of presumed availability and nonavailability of pain relief during labor. It was noticed that the percent's studied antenatal women who expected have moderate and severe labor pain during their current pregnancy $(12.1 \%$ and $89.7 \%$, respectively) opted to deliver normally in case of non-availability of, the previous percentage decreased to $(8.7 \%$ and $82.3 \%$, respectively) in case of presumed availability of LA. Furthermore, the availability of pain relief during labor may decrease CS by more than $50 \%$ in women had moderate and severe labor pain during their current pregnancy compared to non-availability of pain relief $(9.6 \% \mathrm{VS}$ $22.7 \%$ and $8.2 \%$ VS $28.1 \%$, respectively). There is highly statistically significant difference.

Table (8) : shows that there is no statistically significant difference between the participant's parity and their knowledge about labor analgesia.

\section{Discussion}

This study was conducted on (814) antenatal women who were in the third trimester of their pregnancies and planned to be delivered normally in Assiut university hospital, to assess their knowledge, attitude and acceptance for pain relief methods during labor and to know the effect of presumed availability of pain relief on their choice the mode of delivery. The mean age of women in this study was 26.1 years, nearly half of them were secondary education or more, the majority of them were not employed and more than half were residence in rural areas and experienced with normal delivery. In the present study, the participant women mentioned that the main reason for their preferred C.S. delivery was labor pain. This finding in the same line with a study conducted in Assiut by Abdel-Aleem et al., (2011) who found that good part of caesarean section rate increase was probably caesarean section on demand. Good part of this decision was based on fear of pain during labor.

Pain relief in labor is an important issue in the management of pregnant women in childbirth and there are an increasing number of women worldwide who using labor analgesia as a pain management strategy during labor. It has been observed in the current study that the majority of women had no knowledge about labor analgesia (82.9\%). From the point of the researchers' view this poor knowledge of women about human reproduction and LA is due to lack of antenatal education and counseling about LA in Assiut woman's Health Hospital and the limited ability to seek and access information and view of the high workload and shortage of nurses. Also, our public health system does not provide sufficient cognitive and emotional preparation for our obstetric patients. In the same line, Shidhaye, et al., (2012) study revealed that almost all of the study group $(98.48 \%)$ irrespective of age, education level, socioeconomic status, were not having any information about labor analgesia. Similarly, Barakzai et al., (2010) performed a study at Obstetric Out- Patients Department of Liaquat University of Medical and Health Sciences among 131 women to assess awareness of women regarding analgesia during labor and found that less than half of the women aware of labor pain relief methods. Also, the current study was supported by Naithani et al., (2011) study that found $(9.5 \%)$ of the studied group was aware about LA.

Moreover, results of this study have shown that the main source of information for the study participants were friends or relatives. This can be attributed to Egyptian cultural practices as majority of the females feel comfortable to discuss personal matters with friends while doctors have a strong influence over decision making in health seeking practices. This previous finding agreement with Mung'ayi et al., (2008) study in Nairobi showed that friends, the antenatal clinic and books/leaflets were the major source of information about pain relief methods. While James, et al., (2012) who found his survey that the most of the women $(78 \%)$ had heard about methods to relieve labor pain mainly through the media and through their doctor.

The main domain in this study was to know attitude of women to pain relief. The result of present study revealed that the past experiences of labor pain were graded as severe as 10 and the expected labor pain were graded as severe as 8-9. This result was 
supported by Ibach et al., (2007) conducted a study at a local midwifery obstetric unit in Cape Town among 30 healthy Xhosa-speaking women who presented for antenatal care, found that the past experience and expected labor pain were graded as severe as 8.4 and many women were afraid and scared of labor pain. In contrast, Naithani et al., (2011) conducted a study in India among 200 antenatal women for taking part in a semi-structured interview and found that past experience and expected labor pains were graded as mild or moderate as 3 or 4; and most of the women were confident that they could cope with the labor pains.

Pain relief in labor is an important issue in the management of pregnant women in childbirth. Concerning participants' opinion regarding labor analgesia, the results of the present study revealed that the majority of women preferred pain relief during labor. The same finding was reached by Olayemi et al., (2003) who found that about two thirds of the respondents in the Nigerian study were willing to accept analgesia if offered. On the other side, the most common reason for refusal LA cited by the present study was the desire of antenatal woman to experience normal delivery. This can attributes due to traditional values according to which pain in labor is considered a positive feature of labor and the idea of relieving it is often opposed. Similarly, Mugambe et al., (2007) found that most of the women believed that they should experience pain during labor.

The other domain in this study was to know the effect of presumed availability of relief pain on antenatal women's choice the mode of delivery (vaginal vs. cesarean section). When the option of availability of LA offered, the vast majority of the studied antenatal women opted to deliver normally and slightly less than one tenth opted to give birth by C.S. with statistically significant differences (P. 0.001). Furthermore, the present study's results found that there is highly statistically significant relation the choice of N.D/C.S and their expected labor pain ( $p=$ 0.001 ) in case of non-availability of pain relief and availability of pain relief. These finding are supported by Abdel-Aleem et al., (2011) who reported that making painless labor or increase availability of pain relief during labor may decrease CS on demand and can decrease CS rate.

Finally, we believe that the current study represents one of the comprehensive attempts to document the effect of the participant's labor pain on their choice of mode of delivery in case of presumed availability and non- availability of pain relief during labor. As with any research, however, there are limitations to this study that should be considered when interpreting the results. The results of this study in Assiut City may not generalize because the study sample is small. In addition the study was conducted at a single setting (Woman's Health Hospital in Assiut University), thus limiting the reliability of the data which could have been gained from basing it in multi- setting.

\section{Conclusions}

Based on the present study findings, it can be concluded that there is a lack of knowledge regarding the need for pain relief during labor, the various types of labor pain relief methods and their advantages and disadvantages. There is statistically significant relation between participant's labor pain and desire of N.D/ C.S in case of presumed availability and nonavailability of pain relief during labor.

\section{Recommendations}

Future studies including post-partum data need to detect the association between fear of childbirth and women's knowledge about painless childbirth. Future study would be great in examining the effect of educational program on increasing women's awareness, perception and attitudes. Antenatal women should be educated and counseled about the need for labor analgesia and the available options by the provision of information leaflets, labor pain websites and childbirth preparation classes.

\section{References}

1. Barakzai A., Haider G., Yousuf F., Haider A ,and Muhammad N., (2010): Awareness of women regarding analgesia during labor. Journal of Ayub Medical College Abbottabad, Vol. 22, Issue 1, Page 73: 75.

2. E Ogboli Nwasor, SE Adaji, S., Bature and O., Shittu, (2011): Pain relief in labor: a survey of awareness, attitude, and practice of health care providers in Zaria, Nigeria. Journal of Pain Research August 2011, Vol. 4, Page 227:232.

3. Fan, Z., Gao, X., and Yang, H., (2007) "Popularizing labor analgesia in China," International Journal of Gynecology and Obstetrics, vol. 98, no. 3, pp. 205-207.

4. Gita Arjun, (2008): Caesarean section: Evaluation, guidelines and recommendations. Indian Journal of Medical Ethics July-September 2008, Vol. V No 3, Page 117: 120.

5. Abdel-Aleem H., Shaaban O., Hassanin A., and Ibraheem A., (2011): Analysis of caesarean section cases in Assiut University Hospital using ten group classification.

6. Health Sciences Centre, (December 2008): Pain Management for labor \& Delivery. Winnipeg, Departments of Anesthesia, Obstetrics and Obstetrical Nursing. 
7. Henry A., and Nand S., (2004): Women's antenatal knowledge and plans regarding intrapartum pain management at the Royal Hospital for women. Australian and New Zealand Journal of Obstetric and Gynecological August 2004, Vol. 44, Issue 4, Page 314: 317.

8. Hildingsson $\mathbf{I}$., $\mathbf{R}^{\circ}$ adestad I., Rubertsson, $\mathbf{C}$., and Waldenstr U., (2002): "Few women wish to be delivered by caesarean section," BJOG, vol. 109, no. 6, pp. 618-623.

9. Ibach F., Dyer R., Fawcus S, Dyer S., (2007): Knowledge and expectations of labor among primigravid women in the public health sector. South Africa Medical Journal June 2007, Vol. 97, Issue 6, Page 461: 464.

10. International Institute for Population Sciences and Macro International, (2006): Report of the National Family Health Survey (NFHS - III. Mumbai: IIPS, Pp. 1: 24.

11. James J., Prakash S., and Ponniah M., (2012): Awareness and attitudes towards labor pain and labor pain relief of urban women attending a private antenatal clinic in Chennai, India. Indian Journal of Anesthesia March - April 2012, Vol. 56, Issue 2, Pp. 195,198.

12. Mugambe J., Nel M., Hiemstra L., and Steinberg W., (2007): Knowledge and attitude toward pain relief during labor of women attending the antenatal clinic of Cecilia Makiwane Hospital, South Africa. South Africa Family Practice Journal, Vol. 49, Page 16: 16 d.

13. Mung'ayi V., Nekyon D., Karuga R., (2008): Knowledge, attitude and use of labor pain relief methods among women attending antenatal clinic in Nairobi. East Africa Medical Journal September 2008, Vol. 85, Issue 9, Page 438: 441.

14. Olayemi O., Aimakhu C., and Udoh E., (2003): Attitudes of patients to obstetric analgesia at the University College Hospital, Ibadan, Nigeria. Journal of Obstetric Gynecological (January 2003), Vol. 23, Issue 1, Pp. 38: 40.

15. Onah H., Obi S., Oguanuo T., Ezike H., Ogbuokiri C., and Ezugworie J., (2007): Pain perception among parturients in Enugu, Southeastern Nigeria. Journal of Obstetric and Gynecological (August 2007), Vol. 27, Issue 6, Pp. 585: 588.

16. Orange F., Passini J., Melo A., Katz L., Coutinho I., and Amorim M., (2012): "Combined spinal-epidural nesthesia and nonpharmacological methods of pain relief during normal childbirth and maternal satisfaction: a randomized clinical trial," Revista da Associacao Medica Brasileira, vol. 58, no. 1, pp. 112-117.
17. RV Shidhaye, M., Mandar Galande, MBBS, V., Bangal, M., Joshi Smita, M., Uttara Ramchandra Shidhaye, MBBS, DGO, (2012): Awareness and attitude of Indian pregnant women towards labor analgesia. An International Journal of Anesthesiology, Pain Management, Intensive Care \& Resuscitation, Vol. 16, Issue 2, Pp. 131: 136.

18. Ajeet S, Jaydeep N., Kishore K., and Nisha R., (2011): Women's knowledge, erceptions and potential demand towards caesarean section. National Journal of Community Medicine July Sept 2011, Vol 2, Issue 2, Pp. 244, 248.

19. Naithani U., Bharwal P., Chauhan S., Kumar D., Gupta S., and Kirti, R., (2011): Knowledge, attitude and acceptance of antenatal women toward labor analgesia and caesarean section in a medical college hospital in India. Journal of Obstetric Anesthesia and Critical Care Jan - Jun 2011, Vol. 1, Issue 1, Pp. 13: 20. 